\title{
HISTORIA Y ESCRITURA FEMENINA EN OLGA NOLLA, MAGALI GARCIAA RAMIS, ROSARIO FERRÉ Y ANA LYDIA VEGA
}

POR

\author{
MARÍA I. ACOSTA CRUZ \\ Clark University
}

Las cuatro escritoras puertorriqueñas de las que escribo estudian la interacción de la escritura y la historia para presentar nuevas definiciones de laidentidad femenina y de la identidad cultural puertorriqueña. Estas autoras pertenecen a la primera generación coherente de narradoras en las letras puertorriqueñas. ${ }^{1}$ Son parte de un grupo de escritoras que surge en las décadas de 1970 y 1980 y cuya fama, en lo que respecta a Ferré, Vega y García Ramis (Nolla es mucho menos conocida), al canza o supera la de sus colegas masculinos. ${ }^{2}$ Sus experiencias formativas incluyen el feminismo, siendo éste el elemento más valioso de los que ellas aportan a la literatura puertorriqueña contemporánea. Sus textos, aunque diferentes en muchos respectos, evidencian preocupaciones feministas, como el análisis de la otredad, el estudio del rol de las minorías en la historia, la exploración de la identidad cultural e individual, y la desconstrucción de los mitos patriarcales de la nación y la familia. Su proyecto feminista no es reduccionista, ya que estas autoras examinan muchos otros elementos de la cultura puertorriqueña, especialmente la dimensión política. Ejemplo de esto es que Juan Manuel García Passalacqua lee las obras de García Ramis y Ferré en referencia a problemas de clase y política sin aludir siquiera al elemento feminista. Pero es de la unión del feminismo con otras vertientes culturales que surge la actitud cuestionadora hacia la escritura histórica que quiero enfocar aquí.

\footnotetext{
"Empleo el término "generación" consciente de su utilidad tanto como de sus limitaciones, en especial de la aplastante unificación de elementos a veces irreconciliables entre diferentes autores. Pero quiero aclarar que Rosario Ferré es, en este caso, algo así como una figura fundacional a la que las demás autoras siguen.

2 Margarite Fernández Olmos detalla las causas históricas del surgimiento de esta generación de autoras. Edna Acosta-Belén presenta un resumen crítico de lo que llama Generación del 70. Efraín Barradas examina el surgimiento de las autoras dentro del cuadro general de autores de la época.
} 
La pregunta que guía mi lectura es ¿cómo se reconstruye y recupera la historia en las obras de estas autoras? Me refiero específicamente a problemas tales como: 1) qué es la "historia" y qué papel juegan las mujeres y los marginados en la historia oficial?; 2) ¿cómo afecta la presencia o ausencia de la historia a la constitución de la identidad femenina?;3 y 3) ¿cómo puede la mujer re-escribir la historia? En términos generales las autoras que estudio concluyen que: 1) la historia está sujeta a las reglas, restricciones e intereses ideológicos típicos de una narración; 2) ya que la femineidad no es un estado natural, sino una construcción cultural, la identidad femenina depende, en parte, de su presencia continua en la historia y 3 ) la mujer tiene que re-escribir la historia para insertarse en ella.

En cuantoa la identidad colectiva, o sea la definición de la puertorriqueñidad, los textos tienen diversa relación con el monológico romance nacional que Jean Franco identifica como "the drama of male enterprise or impotence, the search for male identity that depends on the allegorization of women characters" ("Self-Destructing Heroines" 105). Las autoras difieren en cuanto a ese cantar de gesta masculino típico del patriotismo que ha sido elemento formativo de la historia isleña; Ferré lo ataca, Vega lo parodia, Garcia Ramis lo feminiza y Nolla lo descarta. Otros factores determinantes en este tipo de discurso femenino son el rol de la nostalgia y el uso de la parodia en la visión del pasado. Sobresale también el interés de este grupo de autoras por los usos y abusos del melodrama en la cultura popular.

Cada autora enfoca épocas y temas diferentes, pero sus aproximaciones tienen elementos en común, por ejemplo, Nolla, García Ramis y Ferré desenmascaran los mitos culturales puertorriqueños usando la familia como centro figurativo de sus narraciones. Vega, Ferré y, en parte, Nolla ilustran cómo la escritura histórica depende de autores que dibujan un cuadro ideológicamente interesado de la historia. En Ferré y Vega la historia presupone una lucha entre la versión oficial y las versiones silenciadas de los eventos históricos. Es rasgo evidentísimo que cada autora explícitamente contextualiza la(s) ideología(s) no como manifestación de un discurso totalizante, eterno y natural sino según la especificidad histórica que produce esa(s) ideología(s).

Si bien los dos cuentos de Rosario Ferré y Ana Lydia Vega que examino aquí tratan mayormente sobre la historia del siglo XIX, Magali García Ramis y Olga Nolla presentan la historia reciente de Puerto Rico. Estas últimas dos autoras -quienes apenas son conocidas fuera de la isla- desarrollan sus cuadros históricos exponiendo la familia como doble simbólico de la nación. El proyecto historiográfico de Nolla y García Ramis se basa en el desmantelamiento de los mitos de la "familia" puertorriqueña que han ayudado a mantener las relaciones del poder tradicionales.

${ }^{3}$ Distingo aquí entre términos comunes: "mujer" como rasgo biologico, "femenino", como construcción cultural y "feminista" como planteamiento político. 


\section{OLGA NOLLA}

Olga Nolla, autora mayagüezana, presenta en su libro de cuentos Porque nos queremos tanto (1989) la micro-historia de la vida de familia y los sucesos del vecindario como paradigma de la macro-historia del Puerto Rico contemporáneo. ${ }^{4}$ Por ejemplo, en un cuento titulado "La boda del primo Fred" Nolla examina el sobresalto de la clase alta ante el lugar prominente que ocupa la clase media en el Puerto Rico moderno. El cuento describe el encontronazo, durante una boda, de una familia de clase alta con una de clase media-baja. El momento histórico en que estas dos clases finalmente se ven obligadas a compartir el espacio público pone en evidencia los defectos de cada clase, a saber: el refinamiento de la clase alta se perfila como ensimismamiento egoísta y el kitsch sentimentalista de la clase media como oportunismo.

"Un corazón tierno" cataloga la experiencia de desgarrador exilio de toda una generación de puertorriqueños mediante la triste historia de una familia que, obligada por consideraciones económicas, emigra a Nueva York en los años cincuenta. La emigración es un tema frecuente en la literatura puertorriqueña, los autores de la década del cincuenta, por ejemplo, presentan una y otra vez las vicisitudes del trasplante de los campesinos boricuas a la metrópolis niuyorkina. Pero el cuento de Nolla, siguiendo la vertiente feminista, trata de cómo la transición económica y social de esa época impactó a la mujer tanto como al hombre. Aunque la pareja del cuento son unionistas de tendencia radical, no están inmunes a los prejuicios y las ideas preconcebidas de esa época. El cuento es un estudioenternecedor de los efectos destructivos para una familia tradicional cuando la mujer cobra conciencia de su nueva identidad e independencia económica. Nolla describe balanceadamente la creciente responsabilidad y confianza de la mujer junto con la desesperación y frustración del hombre —el "corazón tierno" del título-que no comprende por qué se han perdidolos valores familiares de antes y no encuentra un rol en este nuevo orden socio-económico.

Los dos cuentos mencionados son narrados en la tradicional tercera persona e indagan la historia puertorriqueña reciente enfocando la familia. El cuento "El milagro de la calle del Sol" en cambio, desarrolla una anécdota más o menos contemporánea usando una narración auto-reflexiva y examinando la cultura popular. El cuento relata la situación de una mujer abandonada por su marido, victimizada por su padre y luego por sus tres hijos que a su vez la abandonan cuando crecen. Esa mujer, llamada Rosa, languidece en la pobreza y la desesperación hasta que es "rescatada" por el matrimonio con un cocinero.

\footnotetext{
4 Cabe señalar que los cuentos de Nolla no se sitúan ni en la ruralía ni en el ambiente capitalino usuales en las letras puertorriqueñas. Nolla, como lo hace Ferré con su Ponce natal, coloca la acción mayormente en Mayagüez, "ciudad de provincia autocontenida" como la llama Trelles. Ana Lydia Vega y Magali García Ramis más tradicionalmente ubican sus obras en la capital.
} 
La vida de Rosa es un cuento de hadas contemporáneo que hace eco consciente de las ubicuas telenovelas a que media isla parece adicta.

La anécdota no tiene nada nuevo, lo que sí es diferente es el acercamiento narrativo. El relato es contado por los vecinos de la calle del Sol, una voz de la colectividad que detalla las aventuras de Rosa. La narración desde un principio cuestiona su propia veracidad ya que la voz narrativa afirma que "no nos estamos inventando esta historia, lo juramos por Dios y su Santa Madre y que nos parta un rayo en este instante si no decimos la verdad y nada más que la verdad" (121). La auto-reflexividad narrativa subraya la diferencia entre la descripción de eventos "verídicos" y la ficción telenovelesca. El cuento descentra la verosimilitud del episodio debido a que la voz narrativa tiene conciencia de que el final feliz forzado de la tradición melodramática se reproduce en la historia de Rosa. La narración, una y otra vez, pone en entredicho la "lección" del melodrama ya que, como la descripción de la vida de Rosa deja claro, ¿cuántos pueden ser los finales felices en "este país de mujeres superjodidas?" (120).

La voz narrativa del cuento se aprovecha en forma irónica del modelo de las telenovelas, a sabiendas de que la vida, a despecho de "Simplemente Maria", no termina felizmente. El mito que el cuento ataca es la creencia contemporánea de que la seguridad de la mujer de clase baja depende del "milagro" del matrimonio. La estabilidad económica y emocional de la mujer en el mundo de las telenovelas depende sólo de su rol en la familia. La falta de "veracidad" de la narración subraya la falsedad de dicho sistema económico.

$\mathrm{Al}$ apropiar la estructura del melodrama el cuento además explota la seducción que tienen las telenovelas para la clase media-baja, especialmente para las mujeres: "acostumbramos contarles esta historia a los que visitan nuestro barrio. Nos parece que parece una telenovela y a las personas solitarias suele gustarles mucho. Especialmente a las mujeres divorciadas, porque la vida para ellas es muy dura" (129). Nolla ilustra cómo las ficciones telenovelescas se posesionan de la imaginación popular. En Puerto Rico las telenovelas son actualmente el entretenimiento preferido de las clases que no tienen verdadero poder socio-económico y que, según la voz narrativa, rechazan "los libros" ya que "son aburridos y dan sueño" (126), o sea que repudian la "literatura" que, en el caso de Puerto Rico, siempre ha tratado de crear conciencia de las disparidades económicas y sociales.

El cuento subraya la distancia entre la alta cultura tradicional y la cultura de masas tan popular con las clases media y baja. Jean Franco afirma que, debido a la industrialización de las décadas del cincuenta y sesenta en Latinoamérica, "oral narrative became market literature or was replaced by the soap opera and the photonovel" ("What's in an Name?" 8). En el cuento de Nolla ese proceso se invierte, los vecinos de la calle Sol transforman la telenovela en narración oral. Esa transposición es un gesto ambiguo de complicidad y de crítica hacia la cultura popular. 


\section{MAGALI GARCIA RAMIS}

En su exitosa novela Felices días, tío Sergio (1986) Magali García Ramis feminiza la narración épica masculina escribiendo un bildungsroman femenino situado en la década de 1950, la época del desarrollo muñocista caracterizado por la industrialización de la economía y la urbanización del paisaje. Lidia Solís, la protagonista, narra en forma realista su crecimiento desde la niñez a la adolescencia - "esa edad cuando en vez de formarse uno se está rompiendo"(135) - en el regazo de una familia de clase media de ideología conservadora.

García Ramis, como Ferré, desmitifica la familia a la vez que la utiliza como paralelo de la nación. Felices días, tío Sergio es el cuadro intimista de una familia que, pese a sus peculiaridades e historias particulares, equipara el desarrollo económico e ideológico de la isla en esa época.

García Ramis y Ferré en "Maldito amor" ambas toman sus títulos de las canciones tradicionales llamadas danzas. García Ramis usa el título de una danza que canta el desconsuelo ante la memoria del tiempo perdido mientras Ferré toma una danza de tradicional amor frustrado. ${ }^{5}$ La presencia textual de esas danzas tiñe los textos con una combinación ambivalente de ternura, ironía, sentimentalismo y nostalgia, a la vez que recalca la cultura popular y subraya el rol de la música popular en la construcción de la identidad nacional puertorriqueña.

Hay que apuntar que Ferré - como Nolla con las telenovelas- usa las danzas en un contrapunto irónico que destaca las insuficiencias del melodrama para interpretar la realidad. García Ramis usa la música popular en forma menos polémica. Para Lidia, la protagonista, la música popular representa la expresión directa del sentimiento popular que está más aliado, para García Ramis, con la reafirmación inequívoca de una identidad nacional que con su aspecto de objeto de consumo.

La nostalgia, de por sí, tiene un matiz de re-escritura historia, de búsqueda del tiempo perdido, de rescate de la historia querida y por lo tanto presenta el pasado en una luz al menos parcialmente positiva. No quiere decir que la rememoración nostálgicajuzgue positivamentela totalidad del momento histórico observado; en realidad García Ramis encuentra mucho más para criticar que para alabar, así como Ferré subvierte las danzas al usarlas como marco de acciones violentas.

En Felices días, tío Sergio la nostalgia es el sentimiento ambivalente que reconcilia la estupidez del sistema de valores de esa clase, en ese momento histórico, con los elementos positivos de la vida en familia, como el cariño y la solidaridad de una tribu familiar que ni siquiera en la muerte abandona a los

\footnotetext{
${ }^{5}$ Pueba de lo ubicuas que son estas danzas es que Ferré también usa la letra de "Felices días" en su cuento "La caja de cristal".
} 
suyos. La estabilidad de la familia Solís se sitúa en el contexto histórico-que García Ramis dibuja minuciosamente- de la seguridad de la "Pax muñocista", cuando casi no existía la criminalidad, ni el problema de las drogas, ni cualquiera de la plétora de problemas sociales que afectan el Puerto Rico contemporáneo.

El cerco sentimental de la familia - reforzado en la novela por la naturaleza colectiva de las finanzas familiares-hace que la protagonista tenga un sistema de lealtades sumamente complicado ya que cualquier intento de establecer una identidad fuera de la familia es un acto de traición a la unidad familiar. Como en los cuentos de Nolla, los conflictos familiares son mediatizados por ese "querernos tanto" que complica y profundiza las divisiones faccionales e ideológicas.

Lidia, la narradora, detalla el proceso de educación en familia, con su inculcación de los valores y prejuicios típicos de la clase media puertorriqueña de los años cincuenta: "nos iban educando con una mezcla de conceptos científicos y religiosos, verdaderos y falsos, liberales y conservadores, producto de sus miedos y prejuicios" (28). El mundo más allá de la familia se divide en dos: el lado del Bien donde están: el catolicismo, los Estados Unidos, Europa, la raza blanca, y la zarzuela. El lado del Mal abarca a los comunistas (en especial Fidel Castro, ese vecino amenazante), el ateísmo, las naciones negras de Africa, los nacionalistas y el mambo (28). Como se puede ver en este listado el tono cómico de la narración nivela la seriedad del conservadurismo burgués resaltando el extremismo absurdo de esas creencias. Con una inflexión a la vez burlona y enternecedora la novela presenta la fe ciega de la familia en ideas recibidas, como por ejemplo el recuerdo de la prima Nati gritando que los comunistas son el anticristo.

La caracterización novelística también contrarresta la presentación de la familia como típica clase media conservadora. No hay aquí personajes bidimensionales, ni siquiera la misma prima Nati, a quien Lidia recuerda como una figura interesante: "como si fuera entre científica y maga [...] llevando en la mano un maletín de cuero negro del que salía la cabeza de un conejo con mirada bonachona" (74). Todos los personajes son complicados y humanos, en especial la madre de Lidia, joven viuda ultraconservadora, creedora en la disciplina estricta, pero feroz defensora de sus hijos.

No obstante, para crecer, Lidia tiene que desprenderse del control familiar rechazando dos áreas de "sabiduría" recibida: la política asimilista conservadora de la época muñocista y el rol de la mujer como servidora y madre que el misoginismo católico le transmite a Lidia pese a que las mujeres de la familia son cosmopolitas de clase media-alta y representan un nuevo sector de mujeres en la historia de Puerto Rico: la clase profesional. La contradicción entre las creencias familiares y la realidad histórica de la época es evidente ya que la mayoria de las mujeres en la novela tienen trabajos representativos de esa nueva fase histórica: la madre y una tía son enfermeras, una tía es secretaria, 
otra tía trabaja en la burocracia gubernamental, una prima es tecnóloga médica y otra tía es doctora. Lidia por eso crece -como tantas niñas de esa época-con la expectativa de que será respetuosa, sumisa, recatada, y todas las cualidades femeninas tradicionales, pero a la vez se da por entendido que cursará estudios superiores y tendrá una profesión.

El tío Sergio del título, que llega de Estados Unidos un día y se queda por unos años con la familia, es la figura definitoria para Lidia porque, además de ocupar el lugar del padre ausente, representa un contrapunto ideológico al resto de la familia. Con él se completa el proceso de crecimiento de Lidia ya que él es filtro de acceso a realidades políticas y eróticas vedadas por la familia. Es un hombre diferente al resto de la familia; amigo de nacionalistas, sus ideas radicales están en conflicto con la ideología de la casa. Y para colmo trae consigo la apreciación del arte que abre para Lidia toda una serie de nuevas valoraciones del mundo. El tíoSergio también despierta en Lidia un deseo eróticoinalcanzable e imposible. Para Lidia el crecimiento ideológico está ligado a sentimientos eróticos, como demuestra su descripción de los elementos que hacen diferente al tío Sergio: "su irreverencia, su mal llamada por mi familia 'vulgaridad', su destino, al parecer tan ajeno al nuestro, su mirada de tristeza, sus cartas mensajeras de dolor, y su olor, sobre todo yo insisto en su olor" (80). El tío Sergio es en todo sentido "lo prohibido" y por eso su aparición es tan contundente para Lidia.

Al final Lidia, ya hecha mujer, rechaza el ceñido control familiar y se compromete con los principios del nacionalismoindependentista, no sólo por ser las creencias del tío Sergio, sino por creer que es la forma ideal de contrarrestar la pérdida de identidad colectiva que representó para su generación la vida en el intersticio de dos culturas durante la época muñocista. Felices días, tío Sergio explica no sólo la época muñocista sino también el radicalismo nacionalista de la generación de los años sesenta. En este sentido García Ramis no cuestiona - como lo hacen Ferré y Vega - el nacionalismo y el radicalismo de la época subsiguiente, en parte, claro, porque la novela se concentra en la década del cincuenta.

\section{ROSARIO FERRÉ}

Rosario Ferré también usa un tono parcialmente nostálgico en su visión del pasado, pero en su relato "Maldito amor" (1986). ${ }^{6}$ Ferré principalmente parodia el romance nacional patriótico de la clase gobernante. Es notable la mezcla de nostalgia e ironf́a con que esta famosa autora dibuja el ambiente de la clase alta en Puerto Rico desde fines de siglo XIX a mediados del XX. Ferré presenta la historia no como verdad objetiva, sino como una narrativa que existe en relación

- El relato resulta inclasificable en términos de género, siendo llamado diversamente cuento, novela corta, "texto", "ficción", y (por la autora) novela. 
al rol social y la identidad de la mujer. Su ficción desmantela la 'historia' mostrando la versión femenina del pasado. Usando técnicas narrativas que critican la noción de la autoridad, Ferré parodia las formas narrativas tradicionales y crea una voz narrativa múltiple para las mujeres en el relato. Su escritura también ofrece perspectivas culturales irónicas sobre las danzas y las novelas históricas sentimentales. Pero sí es diferente a García Ramis, y especialmente a Vega, en que no predomina el humor en su tratamiento de la historia.

"Maldito amor" narra la historia de una familia de clase alta, usando narraciones contradictorias juxtapuestas, una lucha de escrituras resueltas a capturar el poder ideológico subyacente en la historia. Mustrando la historia del país por la de una familia, Ferré da una visión detallada del desarrollo económico de Puerto Rico desde la época del monocultivo de la caña hasta el comienzo de la industrialización. Dentro de ese cuadro histórico Ferré privilegia las voces femeninas que han sido escondidas por la historia oficial.

La narración tradicionalista en el relato, que es masculina y burguesa, es interrumpida y corregida por una narrativa femenina que es irónica, deceptiva, fragmentada y discontinua. El relato presenta tres narradoras: Titina, una sirvienta negra, Laura, una matriarca rica, y Gloria, la sirvienta/enfermera viuda del heredero de la familia, quien pone fin a la historia y la narración al quemar la casa señorial. Estas narradoras, cuyas historias se contradicen y se suplementan, forman una voz narrativa "colectiva" que presenta la historia secreta de acuerdo al punto de vista de las mujeres.

En efecto, la enmarañada historia de la familia es contada por un total de cinco narradores, uno de los cuales, con el insólito nombre de Hermenegildo, está escribiendo una crónica/novela de la familia y sirve como centro paródico del relato. El concepto de la historia de Hermenegildo depende de un código de comportamiento burgués que esconde toda falta familiar para conservar a su favor la opinión pública y por lo tanto el poder social. Su narración suprime el punto de vista femenino no sólo por sexismo sino por temor a lo que puedan revelar sobre las manipulaciones políticas y la composición racial de la familia. Por ejemplo, Hermenegildo empieza la historia con el recuento melodramático de los problemas en el matrimonio fundador de la familia, pintándolo de forma tal que la mujer se distingue por su sufrida naturaleza de joven flor de la aristocracia local mientras su marido es el altivo y abusador negociante español. Ese fácil binomio América-España es negado por las versiones de las mujeres, quienes afirman que el marido en realidad era un hombre negro de la comarca. La narración de Hermenegildo ilustra cómo el sentimentalismo y el melodrama -dados a perpetuar estereotipos- pueden servir a los fines oscurantistas del punto de vista conservador.

Hermenegildo hace una identificación interesada entre familia y país. Su proyecto histórico es la glorificación de una gesta patriótica burguesa. Hay que leer las secciones "escritas" por Hermenegildo como una parodia del monológico 
romance nacional y ciertamente hay alguna intención humorística en el lenguaje bombástico que identifica a Hermenegildo. Con la escritura de Hermenegildo el relato caracteriza la noción nacional del patriotismo como un cantar de gesta exclusionario que limita las voces marginadas. La escritura de Ferré endorsa el feminismo y precauciona contra la fal ta de juicio crítico en la participación en las estructuras políticas tradicionales y el nacionalismo patriarcal.

El patriotismo de Hermenegildo forma parte del proyecto histórico patriarcal que construye la identidad nacional exaltando protagonistas individuales (siempre masculinos) en una saga burguesa. La puntada de reverso de dicha saga es, en "Mal dito amor", la narración colectiva femenina, que es también una narración interesada - como lo son todas las narraciones en el relato-pero cuyo sesgo es en favor de los marginados que no han tenido un rol en la escritura de la historia.

El uso en el relato de las danzas tradicionales, canciones formativas de la cultura puertorriqueña decimonónica, introduce una nostalgia irónica que reexamina la formación de la identidad cultural puertorriqueña. Su visión es irónica, ya que la violencia de la vida de familia es un contrapunto al sentimiento a veces empalagoso de las canciones.

\section{ANA LYDIA VEGA}

La escritura de Ana Lydia Vega va más allá de la ironía. Sus cuentos se distinguen de los de las otras autoras por el implacable uso de la parodia y el humor. La diferencia entre la parodia de "Maldito amor" y los cuentos de Vega es que en estos últimos predominan, junto con un enfoque feminista, la irreverencia y la intención humorística.

En Pasión de historia (1987) Vega, como Ferré, enfoca las distorsiones del discurso histórico haciendo hincapié en que la historia (lo que llama el "cucarachero histórico") es incontrolable y por lo tanto todo discurso ideológico que controle la historia es sospechoso. Ella ha dicho al respecto:

En mi proyecto inicial está burlarme de la ideología, de los valores sociales, de todas las fuerzas de arriba que forjan el carácter y comportamiento de la gente (Geisdorfer Feal 152).

En el cuento titulado "Sobre tumbas y héroes" - título que anuncia a gritos el espíritu paródico del cuento-Vega utiliza su estilo inimitablemente paródico y humorístico para comentar la subjetividad de la escritura histórica. El enfoque de este cuento no es tanto el rol de la mujer in illo tempore comola escritura histónica misma. Como dice Margarite Fernández Olmos, los cuentos de Vega no tratan solamente sobre la condición de la mujer -aunque destacan este elemento- sino que son "a general cultural critique" (87).

En "Sobre tumbas y héroes" el modelo de escritor es Emanuel Meléndez, un joven historiador de corte tradicionalmente independentista, a quien el texto 
desconstruye llamándolo "Joven Investigador Ansioso por Contribuir al Rescate de Nuestra Historia". Emanuel investiga el asesinato de dos nacionalistas durante el Grito de Lares, un incidente nacionalista ocurrido en 1868. Para suplementar la escasez de pruebas históricas así como para satisfacer su libido Emanuel —dejando a un lado su creencia en la objetividad de La Cienciaacepta la colaboración de una joven colega llamada Guiomar y su tío don Virgilio, quienes le ayudan a reconstruir los pormenores del evento histórico mediante sus contactos con el mundo de los espíritus. Por eso Rosario Ferré dice que en este cuento "el exorcismo se emplea con fines políticos" "La brujería" 7).

La conjunción de espiritismo, independentismo e historiografía forma un texto multivalente en que la sufrida "objetividad" histórica está sometida a múltiples ideologías. Vega le da un tratamiento cómico lo mismo a la historia que al espiritismo, al feminismo o al nacionalismo. Para Vega el sentido del humor es lo que de verdad "rescata" la historia poniendo al descubierto las ideologías escondidas en la escritura histórica.

"Sobre tumbas y héroes" es, como "Maldito amor", un texto plural compuesto de: 1) la voz irónica de una narradora a quien podemos llamar Ana Lydia Vega; 2) los apuntes de Emanuel; 3) la carta-confesión de don Virgilio; 4) un fragmento de crónica colonial; 5) pensamientos de los tres personajes principales; y ese recurso ya característico del arsenal narrativo de Ana Lydia Vega, 6) los subtítulos de los segmentos que comentan, enmiendan o parodian el texto, como por ejemplo "Falso fin de cuento", "Amanece-PartOne", y "Madre sólo hay una (menos mal)".

La estructura descentrada y el lenguaje burlón del cuento representan toda escritura "seria" como esfuerzo pedante sujeto a la idiosincracia personal. Por ejemplo, la tesis investigativa de Emanuel del crimen como una constante en la historia colonial de Puerto Rico es francamente sensacionalista. Usando lo que Vega llama "saludable irreverencia" ("La censura",21) el cuento constantemente se burla de la seriedad de Emanuel, que no deja de ser un personaje simpático, pero cuyas pretensiones de campeón de la objetividad histórica pseudo-científica están destinadas a caer en el ridículo.

Guiomar tampoco escapa el ataque a la solemnidad en la investigación académica pues, aunque Emanuel se equivoca cuando supone que ella escribe "alguna babosería tipo 'El discurso machista en Lope de Vega" (101), el cuento se burla de Guiomar diciendo que ella se dedica a una reivindicación histórica feminista "a ficha limpia" con el título genérico de "El rol de la mujer en las luchas emancipadoras de Puerto Rico" (102). Conste que esta burla la hace la escritora a quien Rosario Ferré ha llamado la más militante escritora feminista en la isla ("Literature and Identity" 15).

El tercer protagonista, don Virgilio, tampoco se libra del tono ridiculizante del cuento. La prosa epistolar de don Virgilio recuerda la escritura de Hermenegildo. Como aquél, su estilo se caracteriza por el tono ingenuamente melodramático y pomposo: "Mi entusiasmo revolucionario me llevó a hurgar en 
el pasado histórico de nuestra patria" (137). A través de este personaje Vega, como Ferré con Hermenegildo, pone en duda la buena fe del patriotismo ciego y del nacionalismo automático. Pero Vega va más allá en su cuestionamiento ya que pone en entredicho todo control ideológico mediante un estilo que democráticamente parodia todo discurso narrativo.

Enamuel, por su parte, es representativo de la "pasión de historia" o sea la indagación encarecida de la verdad de "la Intra-Historia, la épica oculta, la canción de gesta de los supuestamente derrotados" (103). Emanuel centra su tesis políticamente correcta en lo que Vega llama "el tema obligado: la importancia revolucionaria de los líderes asesinados, su identidad netamente antillana" (103). El cuento en su totalidad parodia la búsqueda de la identidad nacional característica del Caribe hispano ya que la "veracidad" sobre el incidente nacionalista es confirmada por el recuento de don Virgilio, quien, muy a lo Shirley MacLaine, resulta ser la encarnación de uno de los protagonistas de los eventos que Emanuel documenta.

Hay que señalar que Emanuel es un escritor mucho más al día que el Hermenegildo de Ferré. Ciertamente el historiador de Vega está muy bien versado en las teorías marxistas y postestructuralistas de la escritura y el poder, así como en la metodología de la historiografía contemporánea. Su visión histórica cuestiona el modelo tradicional de la epopeya nacionalista pues:

Como digno crío del post-Vietnam, prefería creer en la resistencia anónima de toda una gente. Huelgas laborales, marchas estudiantiles, comités vecinales, comandos musicales y atentados poéticos del frente cultural, eso - y no la obra aislada deunos cuantos hombres excepcionales-era lo que habia que estimular y celebrar (113).

Emanuel representa el pensamiento marxista radicalizante de las décadas de los sesenta y setenta cuyo defecto primordial, según Vega, es la absoluta falta de sentido del humor que trae como consecuencia una ausencia de distancia crítica entre sujeto narrador y objeto histórico. La solemnidad de visión de mundo de Emanuel es lo contrario a la visión escéptica de Vega. Emanuel escribe con toda una serie de predisposiciones ideológicas y tiene una agenda didáctica, esto lo incapacita para negociar "algún destape imprevisto del cucarachero histórico" (120).

El texto, cuyo subtítulo es "Folletín de caballería boricua", también parodia estructuralmente el modelo detectivesco de la investigación histórica, ya que las andanzas de los tres protagonistas siguen un ritmojadeantemente aventuresco. El incidente central, en el cual Emanuel y Guiomar van al rastreo de las tumbas de los héroes caídos, tiene elementos de libro de aventuras, misterio, acoso, peligro, anagnórisis y rescate. Además, el episodio tiene un encuentro amoroso, para complacer, dice, burlonamente a los lectores que "echaban de menos el elemento erótico en esta historia" (122). 
Elsa R. Arroyo apunta que los cuentos de Vega son carnavalizados en sentido bakhtiniano, o sea de tono "conscientemente ambivalente, dialógico y descentralizado" (43). En "Sobre tumbas y héroes" la pluralidad de voces narrativas descentra no sólola anécdota histórica que los personajes documentan, sino también el concepto de escritura histórica mismo. Para Vega, lo importante no es la verosimilitud histórica, sino la fantasía, que usa la historia "no para devolverla en forma de crónica, sino para inventarnos, por ejemplo, un nuevo pasado" ("La censura" 20).

Esa invención del pasado es el elemento compartido en los textos aquí examinados. Las múltiples perspectivas sobre la historia puertorriqueña en estos textos de estas autoras tienen como uno de sus elementos constantes el enfoque -cuestionador, irónico, pero ardiente- en la historia marginada, particularmente la femenina. El feminismo de las autoras es indiscutible, pero lo que resalta al ver su actitud ante el proceso histórico es la amplitud de sus comentarios sobre la cultura y la sociedad puertorriqueñas.

\section{Obras Citadas}

Acosta-Belén, Edna. "En torno a la nueva cuentistica puertorriqueña". Latin American Research Review 2 (1986) 220-227.

Arroyo, Elsa R. "Contracultura y parodia en cuatro cuentos de Rosario Ferré y Ana Lydia Vega”. Caribbean Studies 3-4 (1989) 33-46.

Barradas, Efraín. "La necesaria innovación de Ana Lydia Vega: Preámbulo para lectores vírgenes”. Revista Iberoamericana 132-33 (jun-dic. 1985) 547 556.

Fernández Olmos, Margarite. “From a Woman's Perspective: The Short Stories of Rosario Ferré and Ana Lydia Vegan. Doris Meyer y Margarite Fernández Olmos, eds. Contemporary Women Authors of Latin America (Brooklyn: Brooklyn College Press, 1983) 78-90.

Ferré, Rosario. "La brujería en la literatura puertorriqueña". El Nuevo Día (19 de nov. de 1989) 5-7.

Ferré, Rosario. "Literature and Identity in Puerto Rico Today". Plaza: Revista de Literatura 16 (1989) 12-16.

Ferré, Rosario. Maldito amor. México: Joaquin Mortiz, 1986.

Franco, Jean. "Self-Destructing Heroines". The Minnesota Review 22 (Spring 1984) 105-115.

Franco, Jean. "What's in a Name? Popular Culture Theories and Their Limitations". Studies in Latin American Popular Culture 1 (1982) 5-14.

García Passalacqua, Juan Manuel. "Visiones de clase y política". El Nuevo Día (24 de junio de 1986) 43.

García Ramis, Magali. Felices días, tío Sergio. Río Piedras: Editorial Antillana, 1988.

Geisdorfer Feal, Rosemary. "Interview with Ana Lydia Vega". Hispania 1(March 1990) 151-153. 
Herrera, Bernal y Leo Cabranes Grant. "Entrevista a Rosario Ferré". Plaza: Revista de Literatura 16 (1989) 7-11.

Nolla, Olga. Porque nos queremos tanto. Buenos Aires: Ediciones de la Flor, 1989.

Trelles, Carmen Dolores. "Cuentos de Olga Nolla" El Nuevo Día Suplemento(14 de enero de 1990) 12.

Vega, Ana Lydia. "La censura tiene auto". El Mundo. Puerto Rico Ilustrado (11 dic. 1988) 20-21.

Vega, Ana Lydia. Pasión de historia. Buenos Aires: Ediciones de la Flor, 1987. 
